\title{
intuitio
}

Revista do PPG em Filosofia da PUCRS

doi http://dx.doi.org/10.15448/1983-4012.2019.1.32091

\section{SIMPATIA E ALTRUISMO MORAL EM DAVID HUME}

\author{
SYMPATHY AND MORAL ALTRUISM IN DAVID HUME
}

Francisco Alvarenga Junnior Neto'

Isabella Martins Passos ${ }^{2}$

Resumo: A questão de que trata este artigo diz respeito a relação entre simpatia e altruísmo na filosofia moral do filósofo escocês David Hume. No livro Investigações sobre o entendimento humano e sobre os princípios da moral (2004), o termo simpatia é apontado por Hume como sendo a capacidade que um indivíduo possui de ser afetado por situações particulares de outros indivíduos, sendo tal ocorrência de afetação a condição necessária para que se erija um edifício moral. Assim, na busca de aclararmos a relação existente entre a simpatia e a teoria moral altruísta, buscaremos em um primeiro momento demonstrar que em Hume não há uma primazia da razão sobre os sentimentos, mas sim o contrário. Em um segundo momento, será realizado um aprofundamento acerca da simpatia na teoria moral humeana. Por fim, após tais realizações, o intuito será de demonstrar como as elucidações acerca de uma ética altruísta tem suas raízes em Hume e suas elaborações conceituais sobre uma ética fundada nos sentimentos, onde nossas distinções morais se prefiguram como, antes de meras elaborações racionais, advindas da capacidade simpática que nos é própria e nos permite separarmos aquilo que nos agrada e desagrada ao mesmo tempo que nos faz agir de modo interessado no bem-estar dos outros e da comunidade humana.

\footnotetext{
1 Faculdade Jesuíta de Filosofia e Teologia - FAJE. ORCID: http://orcid.org/0000-0003-2453-1132 2 Faculdade Jesuíta de Filosofia e Teologia - FAJE. Orcid: http://orcid.org/0000-0002-8003431X. E-mail: isamsgs@gmail.com
} 
Palavras-chave: Altruísmo; Hume; Simpatia.

\begin{abstract}
The issue dealt with in this article concerns the relationship between sympathy and altruism in the moral philosophy of the Scottish philosopher David Hume. In the book Investigations on human understanding and on the principles of morality (2004), the term sympathy is pointed out by Hume as being an individual's ability to be affected by particular situations of other individuals, such occurrence of affectation being the necessary condition so that a moral edifice can be erected. Thus, in seeking to clarify the relationship between sympathy and altruistic moral theory, we will first try to demonstrate that in Hume there is no primacy of reason over feelings, but rather the opposite. In a second moment, a deepening of the sympathy in the Hume's moral theory will be realized. Finally, after such realizations, the aim will be to demonstrate how the elucidations about an altruistic ethic have their roots in Hume and his conceptual elaborations on an ethics based on feelings, where our moral distinctions are prefigured as, rather than mere rational elaborations, coming from the sympathetic capacity that is our own and allows us to separate what we like and dislike while making us act in an interested way in the well-being of others and the human community.
\end{abstract}

Keywords: Altruism; Hume; Sympathy.

\title{
1 Introdução
}

A questão de que trata este artigo diz respeito a relação entre simpatia e altruísmo na filosofia moral do filósofo escocês David Hume. No livro Investigações sobre o entendimento humano e sobre os princípios da moral (2004), o termo simpatia é apontado por Hume como sendo a capacidade que um indivíduo possui de ser afetado por situações particulares de outros indivíduos, sendo tal ocorrência de afetação a condição necessária para que se erija um edifício moral.

Da consideração da simpatia enquanto uma capacidade natural distintiva da natureza humana que se prefigurado como princípio das avaliações morais, surge, então, a seguinte premissa: se é a simpatia quem torna o agente capaz de exercitar a benevolência e a justiça, a dimensão 
da utilidade como fundamento da moral humeana goza de outro conteúdo que não somente o amor de si.

Tal qual Francis Hutcheson, Hume parece concordar que um ato só assume status altruísta se motivado pelo cuidado com o bem-estar do outro, sem que isso comporte uma motivação egoísta ulterior ou subjacente. E nesse sentido, o escocês se encontraria juntamente ao grupo daqueles que defendem que a existência do altruísmo negaria a existência do egoísmo psicológico, pressuposto por uma teoria do egoísmo normativo ${ }^{3}$. Em outras palavras, se os indivíduos só pudessem agir de maneira egoísta, seria inútil recomendá-los ao exercício do altruísmo.

Assim, na busca de aclararmos a relação existente entre a simpatia e a teoria moral altruísta, buscaremos em um primeiro momento demonstrar que em Hume não há uma primazia da razão sobre os sentimentos, mas sim o contrário.

Em um segundo momento, será realizado um aprofundamento acerca da simpatia na teoria moral humeana, buscando demonstrar em que sentido esta é apontada pelo filósofo escocês como sendo a condição necessária para que o indivíduo seja capaz de distinguir aquilo que o apraz e desagrada e, consequentemente, aquilo que será tomado como moral e imoral.

Por fim, após tais realizações, o intuito será de demonstrar como as elucidações acerca de uma ética altruísta tem suas raízes em Hume e suas elaborações conceituais sobre uma ética fundada nos sentimentos, onde nossas distinções morais se prefiguram como, antes de meras elaborações racionais, advindas da capacidade simpática que nos é própria e nos permite separarmos aquilo que nos agrada e desagrada ao mesmo tempo que nos faz agir de modo interessado no bem-estar dos outros e da comunidade humana.

3 HOBBES, T. Leviatã ou matéria, forma e poder de um estado eclesiástico e civil. São Paulo: Nova Cultural, 1997. 


\section{A importância dos sentimentos para Hume}

Hume, ao ser vislumbrado em comparação com a filosofia vigente em seu período, mostra-se como um filósofo que contraria, de certa maneira, a grande tradição metafísica racionalista que o antecedeu e que se firmara posteriormente a ele. Em meio às grandes ontologias metafísicas acerca do ser, Hume, como um arauto, assume uma posição naturalista frente às questões do conhecimento e da moral. Se, em questões de conhecimento, o que era tomado como verdade era a existência de um ser voltado para sua própria razão, capaz de adquirir conhecimento fechado em si, descrente da percepção sensível do mundo como pressuposto de um conhecimento confiável, o filósofo escocês, na contramão do afirmado, retorna à experiência, às percepções, o fundamento para o conhecimento. Para Hume são as impressões, em última análise, a raiz de todo conhecimento humano, como se pode perceber nas Investigações sobre o entendimento humano e sobre os princípios da moral (2004).

Hume, seguindo o método que pode ser apreciado nos grandes sistemas filosóficos, realiza em um primeiro momento uma elaboração de uma teoria do conhecimento para que, a partir daí, firme-se o edifício moral. Uma boa analogia para esta tendência é a construção de um edifício; no primeiro momento, qualquer construtor buscará se preocupar com as bases daquilo que virá a ser construído para que, no segundo momento, se construa, finalmente, o edifício pretendido.

O filósofo escocês assume nesses dois momentos de sua filosofia a mesma posição naturalista. Em Uma investigação sobre os princípios da moral (2004), na primeira seção, intitulada Dos princípios gerais da moral, Hume afirma, apesar de não ser de forma clara, os sentimentos como princípios da moral em detrimento à razão e demonstra que as escolhas morais surgem dos sentimentos, da experiência, e demonstra que, contrariamente à tradição, a razão possui o papel de expressar, explicar, em um segundo momento, os "porquês" de uma escolha moral, mas que, em 
última instância, escolhas morais têm sua gênese na capacidade de que um sujeito possui de ser afetado pela realidade.

O que é honroso, o que é imparcial, o que é decente, o que é nobre, o que é generoso, toma posse do coração e anima-nos a abraçá-lo. O que é inteligível, o que é evidente, o que é provável, o que é verdadeiro, obtém somente a fria aquiescência do entendimento e, satisfazendo uma curiosidade especulativa, põe um termo a nossas investigações ${ }^{4}$.

Ao considerarmos que a moralidade não é promovida pela razão, nos é possível compreender que Hume argumenta que existe uma incapacidade de se apreender a moralidade como uma relação entre ideias, as quais são objeto da razão. Outro ponto a se considerar, é que, na Investigação sobre o entendimento humano e sobre os princípios da moral (2004), Hume defende que questões de juízos morais surgem de questões de fato. Há, por conseguinte, uma associação entre ideias e impressões ${ }^{5}$ e, assim, aclara-se que a moralidade não é fruto de um conhecimento puramente indutivo que possa ser descoberto por pensamentos inferenciais.

A única tarefa do raciocínio é discernir em cada um dos casos as circunstâncias que são comuns a essas qualidades; observar as particularidades em que concordam, de um lado, as qualidades estimáveis, e, de outro, as censuráveis; e atingir a partir daí o fundamento da ética, descobrindo os princípios universais dos quais se deriva, em última instância, toda censura ou aprovação [...]

\footnotetext{
4 HUME, D. Investigações sobre o entendimento humano e sobre os princípios da moral. Trad. José Oscar de Almeida Marques. São Paulo: Editora UNESP, 2004. p. 229.

5 GUIMARÃES, L. Simpatia, moral e conhecimento na filosofia de Hume. Dois Pontos, Curitiba, v. 4, n. 2, out. 2007. ISSN 2179-7412. Disponível em: https://revistas.ufpr.br/doispontos/article/ view/8185/8131. Acesso em: 30 jun. 2018.p. 209.
} 
Já é tempo de que façam uma reforma semelhante em todas as investigações morais e rejeitem todos os sistemas éticos, por mais sutis e engenhosos, que não estejam fundamentados em fatos e na observação ${ }^{6}$.

Esta passagem demonstra que, apesar de haver uma considerável importância aos sentimentos como pressupostos morais, Hume concede um importante papel à razão ao que tange à moral. Entretanto, essa importância está descrita enquanto capacidade de compreender tendências nocivas ou úteis, porém, sozinha, escreve Hume, ela não basta para que seja produzida qualquer censura ou aprovação. Escreve Hume no apêndice 1, intitulado Sobre o sentimento moral:

A aprovação ou censura que se segue não pode ser obra do entendimento, mas do coração, e não é uma proposição ou afirmação especulativa, mas um ativo sentimento ou sensação. Nas investigações do entendimento inferimos, a partir de relações e circunstâncias conhecidas, algo novo até então desconhecido. Nas decisões morais, todas as circunstâncias e relações devem ser previamente conhecidas, e a mente, a partir da contemplação do todo, sente alguma nova impressão de afeto ou desagrado, estima ou repúdio, aprovação ou recriminação7.

Ao realizar tais considerações sobre os princípios morais, demonstrando que são os sentimentos tais princípios, Hume se coloca à margem de duas grandes tradições éticas, uma anterior a ele e outra posterior: a

\footnotetext{
6 HUME, D. Investigações sobre o entendimento humano e sobre os princípios da moral. Trad. José Oscar de Almeida Marques. São Paulo: Editora UNESP, 2004. p. 231.

7 HUME, D. Investigações sobre o entendimento humano e sobre os princípios da moral. Trad. José Oscar de Almeida Marques. São Paulo: Editora UNESP, 2004. p. 373.
} 
ética da virtude ${ }^{8}$, tendo como principal difusor Aristóteles, e a ética do dever ${ }^{9}$, defendida por Kant.

Já no Tratado da natureza humana (2001), Hume aponta a primazia dos sentimentos sobre a razão no tocante da moralidade, de forma até, aparentemente, mais assertiva e segura, tal qual se pode perceber:

Como a moral, portanto, tem uma influência sobre as ações e os afetos, segue-se que não pode ser derivada da razão, porque a razão sozinha, como já provamos nunca poderia ter tal influência. A moral desperta paixões, e produz ou impede ações. A razão, por si só, é inteiramente impotente quanto a esse aspecto. As regras da moral, portanto, não são conclusões da nossa razão ${ }^{10}$.

Há, ainda, em outra longa passagem, agora da Investigação sobre o entendimento humano e sobre os princípios da moral (2004), uma reafirmação dos sentimentos enquanto princípios da moralidade, conforme se segue:

A razão, sendo fria e desinteressada, não é um motivo para a ação, e apenas direciona o impulso recebido dos apetites e inclinações, mostrando-nos os meios de atingir a felicidade ou evitar o sofrimento. O gosto, como produz prazer ou dor e com isso constitui felicidade ou sofrimento, torna-se um motivo para a ação e é o princípio ou impulso original do desejo e da volição. A partir das circunstâncias e relações conhecidas ou supostas, a primeira nos conduz à descoberta das que são ocultas ou desconhecidas. O segundo, quando todas as circunstâncias e relações estão dispostas à nossa frente, faz-nos experimentar diante desse todo um novo sentimento de censura ou aprovação. A norma da razão,

8 Cf. ARISTÓTELES. Ética a Nicômaco. 2 ed. Brasília: UnB, 1992. p. 138.

9 Cf. KANT. I. Fundamentação da metafísica dos costumes. São Paulo: Discurso, 2009.

10 HUME, D. Tratado da natureza humana. São Paulo: Editora UNESP, 2001. p. 497. 
fundada na natureza das coisas, é eterna e inflexível, até mesmo pela vontade do Ser Supremo"1.

\section{0 papel da simpatia como fundamento da moralidade}

Nos termos humeanos se deve compreender o termo simpatia como a capacidade que um indivíduo possui de ser afetado por situações particulares de outros indivíduos. Hume defende que tal inclinação à afetação é de fácil observação nos seres humanos. Nós, homens, facilmente nos alegramos quando nos deparamos com algo esteticamente belo: uma bela peça teatral, uma boa música, um bom romance, entre outras coisas, mas não só. Hume defende que tal inclinação da elevação do nosso estado conformativo e afirmativo acerca de algo não ocorre somente em situações estéticas, mas também morais. Hume pontua que os sentimentos de prazer e desprazer estão relacionados ao resultado produzido em nós por meio do princípio da simpatia. Este princípio possui um papel central na moralidade humeana. Aqui, e no texto de Hume, simpatia não possui a mesma denotação dada frequentemente ao termo. Não se trata de um sentimento que comunica a um indivíduo $A$ o sentimento que um indivíduo $B$ pode estar sentindo. $A$ simpatia humeana se prefigura como a condição em que o indivíduo $A$ sinta, de alguma maneira, o que o indivíduo $B$ pode estar sentindo como algo sentido por si, como um sentimento particular. No Tratado, Hume escreve:

De fato, é evidente que, quando simpatizamos com as paixões e sentimentos alheios, de início esses movimentos aparecem em nossa mente como meras ideias, e nós os concebemos como pertencendo a uma outra pessoa, assim como concebemos qualquer outro fato. Também é evidente que as ideias dos afetos alheios se convertem nas próprias impressões que

1 HUME, D. Investigações sobre o entendimento humano e sobre os princípios da moral. Trad. José Oscar de Almeida Marques. São Paulo: Editora UNESP, 2004. p. 378. 
elas representam, e que as paixões nascem em conformidade com as imagens que delas formamos. Tudo isso é objeto da mais clara experiência e não depende de nenhuma hipótese da filosofia. A esta ciência só cabe explicar os fenômenos; embora, ao mesmo tempo, devamos reconhecer que estes são em si mesmos tão claros que temos poucas ocasiões para empregá-la. Pois, para além da relação de causa e efeito, que nos convence da realidade da paixão com que simpatizamos, precisamos das relações de semelhança e contiguidade para sentir a simpatia em sua plenitude. E, como essas relações podem converter inteiramente uma ideia em uma impressão, transmitindo a vividez desta para aquela de maneira tão perfeita que nada se perde na transição, podemos facilmente conceber como a relação de causa e efeito pode, sozinha, servir para fortalecer e avivar uma ideia. Na simpatia, existe uma conversão evidente de uma ideia em uma impressão. Essa conversão resulta da relação dos objetos conosco. Nosso eu está sempre intimamente presente a nós. Comparemos todas essas circunstâncias, e veremos que a simpatia corresponde exatamente às operações de nosso entendimento; e contem mesmo algo de mais surpreendente e extraordinário ${ }^{12}$.

Hume não nega estritamente que ao criarmos regras de conduta e valores, o que fazemos é visar a utilidade dessas regras e valores a nós mesmos. Entretanto, o filósofo escocês combate e busca demonstrar que enquanto princípio moral, não é nem o amor próprio nem a pragmática aquilo que fundamenta mais primordialmente a moralidade. Ao contrário do que julgam alguns, em Hume não se verifica a existência de um ceticismo moral. Assim, o escocês perfaz uma tentativa de se desvincular

12 HUME, D. Tratado da natureza humana. São Paulo: Editora UNESP, 2001. p. 354. 
da tradição preponderante em sua época, vinculada a Thomas Hobbes ${ }^{13}$, que relacionava o surgimento da moralidade somente à utilidade egoísta ${ }^{14}$.

[...] todo prazer enlanguesce quando gozado sem companhia, e toda dor se torna mais cruel e intolerável. Quaisquer que sejam as outras paixões que possam nos mover - orgulho, ambição, avareza, curiosidade, vingança ou luxuria -, a alma ou princípio que anima todas elas é a simpatia; não teriam força alguma, se fizéssemos inteira abstração dos pensamentos e sentimentos alheios ${ }^{15}$.

Vale ressaltar que Hume está inserido em determinado ponto da história em que alguns conhecimentos acerca da formação psicológica de um indivíduo ainda não eram conhecidos. Hoje, sabemos que devido a disfunções físico-químicas um indivíduo pode não se comprazer ou sentir repúdio frente a algumas ações - psicopatia. Porém, parece-nos que a simpatia, aos termos humeanos, ainda se apresenta como princípio para a moralidade, uma vez que, salvo exceções, a capacidade de se comprazer e sentir a dor ou alegria de outro indivíduo se demonstra como uma capacidade naturalmente universal, ainda que existam graus de ocorrência diferentes de indivíduos para indivíduos.

Dessa maneira, o que Hume, em seu texto, pretende é reivindicar que a moralidade, antes de uma construção racional formal socialmente aceita, surge de uma capacidade que o indivíduo possui de se sensibilizar. Hume defende que um indivíduo se importa com um outro indivíduo devido

13 HOBBES, T. Leviatã ou matéria, forma e poder de um estado eclesiástico e civil. São Paulo: Nova Cultural, 1997.

14 Em Hume, utilidade aponta para uma distinção entre aquilo que é bom e nocivo de modo que, juntamente com a capacidade simpática, ela estaria no cerne da reflexão acerca daquilo que é bom e agradável não somente para um único indivíduo que avalia um acontecimento ou uma ação, mas vislumbrando um bem social: "Por mais egoísta que seja um homem e por mais remota que sejam as pessoas envolvidas, haverá necessariamente uma escolha ou distinção entre o que é útil e o que é nocivo" (HUME, 2004, p. 306).

15 HUME, D. Tratado da natureza humana. São Paulo: Editora UNESP, 2001. p. 363. 
à uma propriedade natural da mente humana, definido por Hutcheson como "atos reflexos"16, capaz de proporcionar o reconhecimento do outro.

Temos por ventura alguma dificuldade para compreender o poder dos sentimentos humanitários e benevolentes, ou para conceber que a simples visão da felicidade, alegria e prosperidade nos traga prazer, e que da dor, do sofrimento e pesar transmita desconforto? A face humana, diz Horácio, toma emprestados sorrisos ou lágrimas da face humana. Reduza-se uma pessoa à solidão e ela se verá desprovida de todos os gozos, exceto os do tipo sensual ou especulativo, pois os impulsos de seu coração não estarão secundados por impulsos correspondentes em criaturas que lhe são semelhantes. As expressões de pesar e lamentação, embora arbitrárias, inspiram-nos um sentimento de tristeza; mas os sintomas naturais, como lágrimas, gritos e gemidos, nunca falham em produzir compaixão ou desconforto. Os efeitos da aflição nos tocam de uma forma tão vívida que não se pode supor que ficaríamos de todo insensíveis ou indiferentes a suas causas quando um caráter ou comportamento malicioso e traiçoeiro nos fosse apresentado ${ }^{17}$.

Hume postula que não recorremos à razão para realizarmos uma avaliação moral, mas sim a um sentimento simpático, pois, a simpatia, sendo princípio natural da mente, leva o indivíduo, em um segundo momento, à uma reflexão racional sobre a utilidade e a justiça que determinará algo como valoroso e moral, ou como sem valor e imoral. Assim, temos, claramente, uma posição contrária ao edifício moral proposto por Kant,

\footnotetext{
16 HUTCHESON, F. Uma investigação sobre o bem e o mal do ponto de vista moral. In: BUTLER, Joseph; CLARKE, Samuel; HUTCHESON, Francis; MANDEVILLE, B.; SHAFTESBURY, Lorde; WOLLASTON, William. Filosofia moral britânica: textos do século XVIII. 2. ed. Trad. Álvaro Cabral. Campinas: Ed. UNICAMP, 2013. p. 127-178. p. 138.

17 HUME, D. Investigações sobre o entendimento humano e sobre os princípios da moral. Trad. José Oscar de Almeida Marques. São Paulo: Editora UNESP, 2004. p. 286.
} 
no qual a ética parte de uma abstração acerca de como se deve agir para, assim, fundamentar as ações humanas ${ }^{18}$. Em Hume, o processo é claramente contrário. Para o escocês, não é a criação abstrata de valores sobre aquilo que é certo ou errado que determina aquilo que é moral ou imoral. $\mathrm{Na}$ verdade, como se viu no trecho da Investigação sobre o entendimento humano e sobre os princípios da moral (2004), tal compreensão defendida por Kant, para Hume, é improvável, uma vez que é necessário que haja uma situação relacional entre indivíduos, experiência de dor e alegria, para que se possa elaborar conceitualmente como bom e mau, moral ou imoral, aquilo que nos causa sentimentos de prazer e desprazer em um momento anterior a este desenvolvimento conceitual realizado pela razão.

Em geral, é certo que, para qualquer lugar que nos dirigimos, sobre qualquer coisa que refletimos ou conversamos, tudo nos aparece sob a perspectiva da felicidade ou miséria humanas, e excita em nosso coração um movimento simpático de prazer ou desconforto. Seja em nossas ocupações sérias, seja em nossos divertimentos descuidados, esse princípio não deixa de exercer sua vigorosa influência'19.

Nesse sentido, no construto moral de Hume não há ações que são realizadas pelo puro dever desinteressado, discernidas por meio de um exercício da razão - ética deontológica. O que se aproxima do dever kantiano em Hume é aquilo denominado por ele como obrigação interessada, porém, sem que esta obrigação possua qualquer estatuto de a priori racional. Outra característica da obrigação interessada é a sua realização por via do interesse pessoal pelo bem social. Em Hume, devido ao seu "sentimentalismo", uma ação moral não é correlata à uma ação fruto do puro dever, como ocorre em Kant, mas sim uma distinção

\footnotetext{
18 Cf. KANT. I. Fundamentação da metafísica dos costumes. São Paulo: Discurso, 2009.

19 HUME, D. Investigações sobre o entendimento humano e sobre os princípios da moral. Trad. José Oscar de Almeida Marques. São Paulo: Editora UNESP, 2004. p. 288.
} 
realizada em termos de linguagem moral após uma afetação, por meio da simpatia, pelo prazer ou desprazer que uma ocorrência pode gerar no interior do indivíduo.

Tendo explicado a aprovação moral que acompanha o mérito ou virtude, nada mais nos resta senão considerar brevemente nossa obrigação interessada para com eles e investigar o homem preocupado com o seu próprio bem-estar e felicidade não atenderá melhor a seus interesses pela prática de todos dos deveres morais ${ }^{20}$.

Não nos damos conta de que, com essa concessão, teremos aberto o caminho para todas as outras perfeições morais, e não mais podemos coerentemente hesitar diante da benevolência desinteressada, do patriotismo e dos sentimentos humanitários ${ }^{21}$.

\section{0 altruísmo como afirmação de uma resposta simpática}

Pelo considerado, a simpatia, como percepção original e natural, não redutível a quaisquer outras instâncias ou sentidos, se apresenta como característica distintiva da natureza humana e como força propiciadora da avaliação e do comportamento moral. Interações humanas são únicas justamente por causa de sua influência e de sua capacidade de promover a utilidade individual e pública, através da benevolência e da justiça. Com isso, a simpatia explica a capacidade de uma pessoa agir em nome de outra ao perceber seus infortúnios sem que isso lhe traga necessariamente algum

\footnotetext{
20 HUME, D. Investigações sobre o entendimento humano e sobre os princípios da moral. Trad. José Oscar de Almeida Marques. São Paulo: Editora UNESP, 2004. p. 359.

${ }^{21}$ HUME, D. Investigações sobre o entendimento humano e sobre os princípios da moral. Trad. José Oscar de Almeida Marques. São Paulo: Editora UNESP, 2004. p. 315.
} 
benefício exterior, viabilizando com efeito um agir alheio ao que pode ser requerido somente pela consequência. E, de novo, esse sentimento expõe a diferença singular entre o binômio simpatia e utilidade, de Hume, e o egoísmo e utilidade, proposto pela teoria hobbesiana. Porque para Hume, conforme o é para Hutcheson:

Nunca chamamos de benevolente àquele homem que é, de fato, útil a outros, mas, ao mesmo tempo, só tem em mira o seu próprio interesse, sem qualquer desejo essencial de propiciar o bem de outros. Para que haja alguma boa vontade ou bondade real, ela deve ser desinteressada, pois a mais útil ação imaginável perde toda a aparência de benevolência assim que nos damos conta de que ela foi motivada por amor por si ou interesse ${ }^{22}$.

Desta feita, Hume considera haver uma imediata satisfação experimentada pelos homens antes mesmo dos resultantes da benevolência e da justiça quando estes são tocados por imagens de felicidade, alegria, triunfo e prosperidade de si e de outros. São essas imagens, e não os benefícios colhidos de suas consequências, as condições capazes de difundir nos homens, o que ele chama de "um agradável sentimento de simpatia e humanidade"23.

Nenhum esforço da imaginação pode converter-nos em outra pessoa e fazer-nos imaginar que, por sermos ela, colhemos benefícios dessas valiosas qualidades que lhe pertencem. [...] Pontos de vista e sentimentos tão opostos à verdade e uns aos outros não poderiam ter lugar ao mesmo tempo na mesma

\footnotetext{
22 HUTCHESON, F. Uma investigação sobre o bem e o mal do ponto de vista moral. In: BUTLER, Joseph; CLARKE, Samuel; HUTCHESON, Francis; MANDEVILLE, B.; SHAFTESBURY, Lorde; WOLLASTON, William. Filosofia moral britânica: textos do século XVIII. 2. ed. Trad. Álvaro Cabral. Campinas: Ed. UNICAMP, 2013. p. 127-178. p. 142.

${ }_{23}$ HUME, David. Investigações sobre o entendimento humano e sobre os princípios da moral. Trad. José Oscar de Almeida Marques. São Paulo: Editora UNESP, 2004. p. 305.
} 
pessoa. Portanto, toda suspeita de considerações egoístas está aqui totalmente excluída. É um princípio muito distinto que age sobre nosso coração e faz que nos interessemos pela felicidade da pessoa que contemplamos ${ }^{24}$.

Por isso, os efeitos da benevolência e da justiça agradam e são desejáveis por suas consequências úteis ao bem-estar dos outros. Tais efeitos demonstram que a prática da utilidade em Hume é moral, justamente, porque ela é desinteressada na medida em que sua utilidade é anterior à vantagem do sujeito que as colocam em ação. O que faz o filósofo considerar que é necessário renunciar à teoria de que todo sentimento moral é explicado pelo princípio de amor de si e admitir uma afeição natural e de natureza pública prontamente observada na ligação entre os homens ${ }^{25}$ pela boa vontade compartilhada entre eles.

A avareza, a ambição, a vaidade e todas as paixões usualmente (porém impropriamente) subsumidas à denominação "amor de si mesmo" estão aqui excluídas de nossa teoria sobre a origem da moral, não porque sejam demasiado fracas, mas porque não se prestam convenientemente a esse propósito. A noção de moral implica algum sentimento comum a toda humanidade [...]. Ela também pressupõe um sentimento universal e abrangente o bastante para estender-se a toda a humanidade e tornar até mesmo as ações e os comportamentos das pessoas mais distantes em objetos de aplauso ou censura, conforme estejam ou não de acordo com a regra de correção estabelecidos. Apenas o sentimento

\footnotetext{
${ }_{24} \mathrm{HUME}$, David. Investigações sobre o entendimento humano e sobre os princípios da moral. Trad. José Oscar de Almeida Marques. São Paulo: Editora UNESP, 2004. p. 304.

25 HUME, David. Investigações sobre o entendimento humano e sobre os princípios da moral. Trad. José Oscar de Almeida Marques. São Paulo: Editora UNESP, 2004. p. 285.
} 
humanitário anteriormente examinado consegue satisfazer esses dos requisitos ${ }^{26}$.

Nesse sentido, não havendo a consideração do egoísmo pela moralidade humeana, o altruísmo se apresenta ao torna-se compreendido não como auto-sacríficio, mas como sentimento subjacente a vontade de agir em consideração aos demais sem que haja, como explicitado anteriormente, a necessidade de motivos ulteriores de vantagens ou desvantagens para o agente. Assim, tal decorrência implica constatar que se os indivíduos pudessem agir somente de maneira egoísta, seria inútil até mesmo recomendá-los o exercício do altruísmo, colocando em xeque, por este curso, as defesas que sugerem a capacidade do egoísmo psicológico obter sucesso na prescrição do altruísmo moral. Dito de outro modo, a existência do altruísmo nega a existência do egoísmo psicológico como pressuposto pelas teorias do egoísmo normativo de autores como Thomas Hobbes.

Isso ocorre porque qualquer indivíduo que tenha a capacidade de interagir com outros semelhantes terá respostas simpáticas em relação a eles Ihes desejando o bem-estar. E é essa experiência de simpatia e não a perícia em arrazoar de um modo moralmente particular, que explicará a capacidade interessada de solidariedade e atos de generosidade entre os homens. Contanto que o princípio subjacente atenda pelo menos duas características:

[...] ser universal de duas maneiras: ela deve gerar um fator motivacional que todos tenham ou teriam em circunstâncias apropriadas, e também devem ter o mesmo objetivo para todos. Na opinião de Hume, a simpatia é o único fator motivacional que atende a essas condições ${ }^{27}$.

\footnotetext{
${ }_{26}$ HUME, David. Investigações sobre o entendimento humano e sobre os princípios da moral. Trad. José Oscar de Almeida Marques. São Paulo: Editora UNESP, 2004. p. 351.

27 LIPKIN, R. J. Altruism and sympathy in Hume's ethics. Australasian Journal of Philosophy, Sydney, v. 65, n. 1, p. 18-32, mar., 1987. p. 26.
} 
Condições atendidas, com percepções agenciando e sendo agenciadas através das preocupações pelos interesses de seus semelhantes, os homens passam a manifestar uma refinada sensibilidade para todas as distinções morais: "uma forte indignação pelas ofensas feitas às pessoas, uma viva satisfação pelo seu bem estar" ${ }^{28}$. Estados traduzidos por uma linguagem geral, que fixa o louvor ou a censura em conformidade com os sentimentos que nascem de interesses mais gerais e compartilhados em sociedade.

Se os princípios humanitários são capazes, em muitas ocasiões, de influenciar nossas ações, eles devem ter em todos os momentos alguma autoridade sobre nossos sentimentos, fazendo-nos aprovar em geral o que é útil para a sociedade e censurar o que é perigoso ou nocivo ${ }^{29}$.

Essa autoridade pressupõe a concordância entre os homens acerca dos atributos relativos ao que seja louvável ou censurável, através de um ponto de vista $\operatorname{comum}^{30}$, um ponto de vista moral, que mobilizado pelo princípio universal da constituição humana, a simpatia, alimenta alguma classe ou denominação imediata de censura ou louvor com a qual toda a humanidade possa ressoar em acordo e harmonia.

[...] a noção de moral implica algum sentimento comum a toda a humanidade, que recomenda o mesmo objeto à aprovação generalizada e faz que todos os homens ou a maioria deles, concordem em suas opiniões e decisões relativas a esse objeto ${ }^{31}$.

\footnotetext{
${ }_{28}$ HUME, D. Investigações sobre o entendimento humano e sobre os princípios da moral. Trad. José Oscar de Almeida Marques. São Paulo: Editora UNESP, 2004. p. 293.

29 HUME, D. Investigações sobre o entendimento humano e sobre os princípios da moral. Trad. José Oscar de Almeida Marques. São Paulo: Editora UNESP, 2004. p. 294.

30 HUME, D. Investigações sobre o entendimento humano e sobre os princípios da moral. Trad. José Oscar de Almeida Marques. São Paulo: Editora UNESP, 2004. p. 352.

31 HUME, D. Investigações sobre o entendimento humano e sobre os princípios da moral. Trad. José Oscar de Almeida Marques. São Paulo: Editora UNESP, 2004. p. 351.
} 
Com isso, o senso moral se torna capaz de atribuir valores e padrões de correção natural aos indivíduos participantes da linguagem moral. Por meio, exclusivamente, do intercâmbio de sentimentos na vida e convivência sociais os fazendo estabelecer um certo padrão geral e inalterável com base no qual aprovam e desaprovam caracteres e costumes ${ }^{32}$. Com a utilidade, entendida como bem público, se presta como fundamento da parte principal da moral que se refere à humanidade e aos nossos semelhantes ${ }^{33}$. [...] mas é preciso notar que esses princípios são sociais e universais, e formam, de certo modo, o partido da humanidade contra seus inimigos comuns, o vício e a desordem ${ }^{34}$.

Nenhum indivíduo, sobre a influências desses princípios, será totalmente indiferente ao bem público gerado por eles nem totalmente imune a afetação de suas tendências. A própria natureza humana requer certos tipos de associações ou interações entre os indivíduos simpáticos ou por meio de outros princípios originados da simpatia. Portanto, nunca poderia haver um indivíduo completamente solitário tendo ele a natureza verdadeira humana ${ }^{35}$, condição sine qua non da experiência de agradabilidade exposta naturalmente pelas interações humanas.

A ambição de uma pessoa não coincide com a ambição de outra, e um mesmo objeto ou acontecimento não pode satisfazer ambas. Mas a humanidade de um homem coincide com a humanidade de todos os outros, e o mesmo objeto excita essa paixão em todas as criaturas humanas ${ }^{36}$.

32 HUME, D. Investigações sobre o entendimento humano e sobre os princípios da moral. Trad. José Oscar de Almeida Marques. São Paulo: Editora UNESP, 2004. p. 298.

33 HUME, D. Investigações sobre o entendimento humano e sobre os princípios da moral. Trad. José Oscar de Almeida Marques. São Paulo: Editora UNESP, 2004. p. 298.

34 HUME, D. Investigações sobre o entendimento humano e sobre os princípios da moral. Trad. José Oscar de Almeida Marques. São Paulo: Editora UNESP, 2004. p. 356.

35 LIPKIN, R. J. Altruism and sympathy in Hume's ethics. Australasian Journal of Philosophy, Sydney, v. 65, n. 1, p. 18-32, mar., 1987. p. 30.

${ }^{36}$ HUME, D. Investigações sobre o entendimento humano e sobre os princípios da moral. Trad. José Oscar de Almeida Marques. São Paulo: Editora UNESP, 2004. p. 352. 
Na prática, estabelecendo relações que buscam preservar as vantagens da mútua assistência e proteção, uma vez que sendo tomadas como úteis à sociedade, também, são úteis ou agradáveis tanto para a pessoa que as exercitam, quanto àqueles que participam de sua utilidade mediada.

[...] e ainda que essa afecção humanitária não seja em geral considerada tão forte como a vaidade ou a ambição, somente ela, por seu comum a todos os homens, pode prover uma fundação para a moral ou para qualquer sistema geral de censura ou louvor ${ }^{37}$.

Ao postular como bem requerido por todos:

Paz interior de espírito, consciência da integridade, um exame satisfatório de nossa própria conduta: essas são condições muito necessária para a felicidade, e serão valorizadas e cultivadas por toda pessoa honesta que se apercebe de sua importância ${ }^{38}$.

Por fim, o juízo moral encontra efeito por esta dinâmica: ao corrigir as parcialidades das emoções e percepções internas, protegendo todos os indivíduos e a sociedade dos erros das muitas variações das imagens apresentadas aos sentidos da convivência social. Dessarte, faz sentido retomar a responsabilidade encontrada em Hume como obrigação interessada no exercício da benevolência geral e particular39. Condições sem as quais, não seria possível falar em altruísmo na moralidade de David Hume. Altruísmo espontaneamente conduzido e legitimado pela própria natureza humana.

37 HUME, D. Investigações sobre o entendimento humano e sobre os princípios da moral. Trad. José Oscar de Almeida Marques. São Paulo: Editora UNESP, 2004. p. 352.

${ }^{38}$ HUME, D. Investigações sobre o entendimento humano e sobre os princípios da moral. Trad. José Oscar de Almeida Marques. São Paulo: Editora UNESP, 2004. p. 364.

39 HUME, D. Investigações sobre o entendimento humano e sobre os princípios da moral. Trad. José Oscar de Almeida Marques. São Paulo: Editora UNESP, 2004. p. 382. 


\section{Conclusão}

Procurou-se aqui expor o percurso pelo qual Hume considera aquilo que se constitui de forma mais fundamental a moralidade. Para o filosofo escocês a noção de moral implica algum sentimento comum à toda a humanidade que recomenda o mesmo objeto de aprovação generalizada, fazendo com que os homens, ou a maioria deles, concordem em suas opiniões e decisões a respeito do que seja bom ou mau, útil ou inútil à comunidade humana.

Como ocorre a qualquer sistema moral que julga responder ao modo como homens experimentam e ajuízam seus comportamentos morais, Hume empreende a tarefa de apontar o mecanismo responsável por explicar a moralidade de modo com que apareça um princípio que seja universal, compartilhado por todos os homens, capaz de gerar um padrão de correção para os comportamentos tidos como dignos de censura por sua inutilidade ao bem comum.

Nesse intercurso, aparece a simpatia como a afecção humanitária, naturalmente adaptada à mente humana, capaz de ligar os homens entre si ao propiciar a eles tomar parte da felicidade ou tristeza do outro, conduzindo a todos a aprovar ou censurar todas ações que tenham seus efeitos sobre cada um deles. Desse modo, a moralidade se mostra determinada pelo sentimento e define a virtude como qualquer ação ou qualidade mental que comunica aos indivíduos um sentimento agradável de aprovação ou, do contrário, de desaprovação. A simpatia, portanto, é uma característica constitutiva do sistema de raciocínio prático e a natureza humana, inclui por seus efeitos, a capacidade de solidariedade como um dos seus princípios mais centrais e diretivos.

Posteriormente, a razão, assume o papel de direcionar os impulsos recebidos das inclinações, ou afetações, ao conhecimento pela linguagem moral do que seja justo ou injusto de receber louvor por seu caráter de utilidade à sociedade. Mas, é pelo intercâmbio de sentimentos presente na convivência social que é possível estabelecer tal padrão geral, inalterável, com base naquilo que deve ser aprovado ou desaprovado nos costumes humanos. 
A utilidade entra como outro fundamento do sentimento moral na medida em que ela atua, não em referência ao próprio sujeito, mas em vista do benefício aos demais. A prática do bem, alimentada pela tendência de promover os interesses dos outros e trazer felicidade à sociedade humana, é o que permite reconhecer o mérito das ações humanas e recomendá-las a todos os componentes da espécie.

Assim, por ter o humano através da simpatia uma forte ligação com os indivíduos e a sociedade, ele é favorável aos hábitos e princípios que promovem a ordem e que the garantem tranquilidade. Quanto mais ele valoriza a felicidade e o bem-estar geral, mais ele se compromete com a prática da benevolência e da justiça, configurando, dessa forma, uma sociedade naturalmente unida, onde a proteção e a assistência de seus membros se tornam valores objetivamente compartilhados por um ponto de vista comum ou por um ponto de vista moral.

Nesse sentido, o altruísmo, tanto pelo exercício da benevolência particular, quanto pela benevolência pública, se constitui a disposição prática capaz de legitimar a ação uns dos outros e receber aprovação dos homens através da boa vontade geral ao distribuir e compartilhar os bens de estima social. Todos, por mais perturbados ou imorais que sejam, têm alguma capacidade de simpatizar com os outros e, portanto, todos têm alguma razão para agir de forma altruísta, mesmo que nem sempre o façam.

Por tudo isso, em Hume, a moralidade é um fenômeno constatável e inegável e a simpatia, a própria constituição do sentido moral. E contra as teorias do egoísmo moral, demonstra a força de um princípio capaz de unir os agentes sem contrariar aquilo que, pela natureza, Ihes é traduzido como uma obrigação interessada, mesmo que lhes sejam natural tal conduta.

\section{BIBLIOGRAFIA}

GUIMARÃES, L. Simpatia, moral e conhecimento na filosofia de Hume. Dois Pontos, Curitiba, v. 4, n. 2, out. 2007. ISSN 2179-7412. Disponível em: https:// 
revistas.ufpr.br/doispontos/article/view/8185/8131. Acesso em: 30 jun. 2018. https://doi.org/10.5380/dp.v4i2.8185

HUME, D. Tratado da natureza humana. São Paulo: Editora UNESP, 2001.

HUME, D. Investigações sobre o entendimento humano e sobre os princípios da moral. Tradução de José Oscar de Almeida Marques. São Paulo: Editora UNESP, 2004.

HUTCHESON, F. Uma investigação sobre o bem e o mal do ponto de vista moral. In: BUTLER, Joseph; CLARKE, Samuel; HUTCHESON, Francis; MANDEVILLE, B.; SHAFTESBURY, Lorde; WOLLASTON, William. Filosofia moral britânica: textos do século XVIII. 2. ed. Trad. Álvaro Cabral. Campinas: Ed. UNICAMP, 2013. p. 127-178. https://doi.org/10.4324/9780203359891_chapter_ii

LIPKIN, R. J. Altruism and sympathy in Hume's ethics. Australasian Journal of Philosophy, Sydney, v. 65, n. 1, p. 18-32, mar., 1987. https://doi. org/10.1080/00048408712342741 